\title{
Determinants of Rural Household Food Insecurity Status and Coping Strategies in Case of Konso Woreda, Segen Area People's Zone of Southern Ethiopia
}

\author{
Aynalem Moges*, Mada Melkamu \\ Economics Department of Arbaminch University, College of Business and Economics, Arbaminch University, Arbaminch, Ethiopia
}

Email address:

mogesaynalem21@gmail.com (A. Moges), melkamumada2002@gmail.com (M. Mada)

${ }^{*}$ Corresponding author

\section{To cite this article:}

Aynalem Moges, Mada Melkamu. Determinants of Rural Household Food Insecurity Status and Coping Strategies in Case of Konso Woreda, Segen Area People's Zone of Southern Ethiopia. International Journal of Business and Economics Research.

Vol. 9, No. 4, 2020, pp. 202-206. doi: 10.11648/j.ijber.20200904.16

Received: May 22, 2020; Accepted: June 15, 2020; Published: June 29, 2020

\begin{abstract}
The aim of this study was to identify determinant factors and status of household food insecurity in Konso district. The study employed primary data collected from 203 households selected by using simple random sampling method. Binary logistic models and household calorie acquisition methods were employed to identify factors and categorize households into food secured and insecure. The survey result shows that in Konso district, about $80 \%$ households were found to be food insecure and majority households were mildly food insecure. The result of the binary logistic analysis showed that, of the twelve explanatory variables expected to determine household's food insecurity in Konso district, only eight variables significantly determine household's food insecurity situations both positively and negatively at $1 \%, 5 \%$ and $10 \%$ significance level. In the study area, farmland size, education level, off-farm income, livestock number and agro-ecology determine negatively and significantly household food insecurity. On the other hand, family size, dependency ratio and distance from market determine positively and significantly household food insecurity. To solve the food insecurity problem in a rural area like Konso, focus should be given to increase education level, off-farm income, livestock and equal focus is also important to reduce family size through a core rural development strategy.
\end{abstract}

Keywords: Calorie Intake, Coping Strategy, Food Insecurity, Konso, Logit Model

\section{Introduction}

World hunger is on the rise, the estimated number of undernourished people increased from 777 million in 2015 to 815 million in 2016. The vast majority of the world's hungry live in developing countries. Due to this, great efforts have been made by the globe to eradicate food insecurity, hunger and poverty. Millennium development goal one (MDG1) was aimed at fighting the miserable conditions of severe poverty, hunger and food insecurity as one of its eight goals [12, 4].

In sub-Saharan Africa, the current rate of undernourishment is around 23 percent. As it is true in most Sub-Saharan African (SSA) countries, Ethiopia is currently facing food insecurity problems that are induced by environmental crises, demographic and socio-economic constraints, which adversely affect peoples' production system. This has resulted in agriculture being poor for several years to the extent that the country could not adequately feed its population from domestic production and prevailing both chronic and transitory food insecurity $[4,2]$.

Rapid population growth challenged achievement of food security and poverty reduction efforts in Ethiopia. Moreover, 2016 was a challenging year for Ethiopia as it suffered from the worst El Niño impact in the last 50 years. The onset of El Niño combined with failed Belg (spring harvest) and Meher (main harvest) rains in 2015 left 10.2 million people in need of emergency food and nutrition assistance $[13,15]$.

Southern Nations Nationalities Peoples Regional state (SNNPRS) is not exceptional to food insecurity problem. According to the recent estimate 24 percent of the total households in SNNPR are found below poverty line with poverty prevalent more in rural areas than urban areas 
[14]. The poor and the very poor of this region depend on food aid or safety net program to meet 5 percent -25 percent of their basic food requirements even in the normal year $[10,8]$. A study which is done in SNNPR showed that most of the households able to feed itself with sufficient food only for less than six to nine months of a year [1].

Konso district is one of the food insecure areas in the region. During the past period, drought was occurring at intervals of approximately every ten to fifteen years; however, now the trend is worsening with a frequency of drought once every three or fewer years. For more than three decades, the people of Konso district have been facing recurrent or repeated food insecurity. Even though productive Safety net program has been implemented to solve the problem but still it is not solved. Moreover, the erratic and unreliable nature of rainfall distribution is also another challenge of crop production in the area which in turn affects household food security [7]. The PSNP program beneficiary households are reached about 40,627, this is an indicator of the existence of food insecurity problem. To solve the food insecurity problem in the study area, it is better to have enough information about the status and identifying determinant factors. Therefore, this study was designed to determine the status of food insecurity, identify factors affecting household food insecurity and coping mechanisms of the problem in Konso district.

\section{Methodology}

\subsection{Sampling Technique}

Multi-stage random sampling procedure was applied to select 203 households using Yamane (1967) formula. Konso district was purposively selected for this study because; due to drought and other several factors. This district has high number of productive safety net program beneficiaries. This study included two agro ecological zones (mid land and low land). In the first stage, two kebeles from midland and five kebeles from low-land were selected randomly. Therefore, a total of seven kebeles were selected out of thirty-four kebeles from two agro-ecological zones. In the second stage, household lists from selected kebeles were used as a sample frame to select 203 households proportionally and systematically.

\subsection{Analytical Techniques}

This study was used calorie intake method, which needs previous seven days recall of the consumed food by each members of household to measure food insecurity. The data analysis was started with the conversion of the weekly food consumption data into kilocalorie. The converted data was divided into household Adult Equivalent (AE). Following this, the amount of energy in kilocalorie (kcal) available for the household was recorded. Then after, sampled households were classified as food insecure and secure based on the recommended daily food intake of 2,100 calorie per day per person following [3]. Households who consume below this minimum requirement were categorized as food insecure and those households who consume above were considered as food secure. The dependent variable has a dichotomous nature (food insecure or secure households), so binary logistic regression model was used. Food insecurity as a dependent variable, thus, assumes the value of $\mathrm{Y}=1$ if a household is food insecure, 0 otherwise. The data was analyzed using STATA software.

\subsection{Model Specification}

Following Gujarati, the functional form of logistic regression model is specified as follows:

$$
\mathrm{P}_{\mathrm{i}}=\mathrm{E}\left(\mathrm{Y}=\frac{1}{X_{i}}\right)=\frac{1}{1+e^{-\left(\beta_{0}+\beta_{1} x_{1}\right)}}
$$

Here $P_{i}$, is the probability that a given household is being food insecure. For simplicity, we can write (1) as,

$$
\mathrm{P}_{\mathrm{i}}=\frac{1}{1+e^{-z i}}
$$

Where

$$
\mathrm{Z}=\beta_{0}+\beta_{1} X_{1}+\beta_{2} X_{2}+\beta_{3} X_{3}------\beta_{n} X_{n}
$$

The probability that a given household food secure is

$$
1-\mathrm{P}_{\mathrm{i}}=\frac{1}{1+e^{z_{i}}}
$$

Therefore, the odds ratio in favor of food insecure is

$$
\frac{\mathrm{Pi}}{1-\mathrm{Pi}}=\mathrm{e}_{\mathrm{i}}^{\mathrm{z}}
$$

Taking the natural logarithm of (4) we obtain,

$$
\begin{gathered}
\mathrm{L}_{\mathrm{i}}=\ln \left(\frac{\mathrm{P}_{\mathrm{i}}}{1-\mathrm{P}_{\mathrm{i}}}\right)=\mathrm{Z}_{\mathrm{i}} \\
=\beta_{0}+\beta_{1} \mathrm{X}_{1}+\beta_{2} \mathrm{X}_{2}+\beta_{3} \mathrm{X}_{3}+--\cdot----+\beta_{12} \mathrm{X}_{12}+\mathrm{U}_{\mathrm{i}}
\end{gathered}
$$

Thus, the model is specified as follow for this study;

$$
\begin{gathered}
=\beta_{0}+\beta_{1} \text { AGE }+\beta_{2} \text { SEX }+\beta_{3} \text { EDUC }+\beta_{4} \text { FAMINSIZE }+ \\
\beta_{5} \text { FARMINC }+\beta_{6} \text { OFFING }+\beta_{7} \text { CREDUSE }+\beta_{8} \text { LNDSIZE }+ \\
\beta_{9} \text { DISTMKT }+\beta_{10} \text { TLOWN }+\beta_{11} \text { AGECO }+\beta_{12} \text { DR }+\mathrm{U}_{\mathrm{i}}
\end{gathered}
$$

Where, $L_{i}$ is the $\log$ of odds ratio, $Z_{i}$ is the function of $\mathrm{n}$ explanatory variables, $P_{i}$ is the probability of being food insecure, $1-P_{i}$ is the probability of being food secure, $\beta_{0}$ is the intercept of the equation, $\beta_{1}, \beta_{2}, \ldots \ldots . \beta_{12}$ are the slopes of the equation in the model and $X_{i}$ s are the explanatory variables included in the model.

\section{Result}

Food insecurity commonly refers to when people are unable to have "physical and economic access" to food that meets both their nutritional needs and food preferences. Konso district faces high levels of food insecurity, ranking as one of the hungriest districts in the region. To see the current food insecurity status in the study area, the household food 
consumption for the last seven days was converted to a kilocalorie and then divided into a household's adult equivalent and the result divided for seven days. Then, their level of energy is compared with 2,100 calories per day per adult equivalent which is the minimum energy requirement per adult equivalent per day per person in Ethiopia. The result indicates that $80 \%$ of the households in the study area were food insecure and only $20 \%$ of households were food secure. But all those $80 \%$ are not equally insecure because the level of insecurity differs from household to household.

Table 1. Core food security module-based classification.

\begin{tabular}{lll}
\hline Levels of food insecurity & Amount of calories & No of HH in that interval \\
\hline Food secure & Above $2100 \mathrm{Kcal}$ & 41 \\
Mildly food insecure & $1800 \mathrm{Kcal}-2100 \mathrm{Kcal}$ & 65 \\
Moderately food insecure & $1500 \mathrm{Kcal}-1800 \mathrm{Kcal}$ & 58 \\
Severely food insecure & Less than $1500 \mathrm{Kcal}$ & $32 \%$ \\
Total & & 39 \\
\hline
\end{tabular}

Own computations, based on household survey data, 2018.

Furthermore, core food security module analysis result also indicates that, out of $80 \%$ food insecure households $32 \%$ households were found to be mildly food insecure, $29 \%$ of them were moderately food insecure and $19 \%$ of them were severely food insecure. From the result it is possible to say in Konso district majority households were mildly food insecure.

\section{Discussion}

Rural household food insecurity in the study area is determined by many factors. Important explanatory variables that were expected to determine household food insecurity status in Konso district were selected based on literature review and experience. Binary logistic regression model was employed to identify the determinants of household food insecurity. Prior to parameter estimation of logit model, tests for multicollinearity using the variance inflation factor for continuous variable, contingency coefficient for dummy variables and also link test for model specification were performed for validation of the estimated model, the data has no serious problem with these. Since interpreting the result directly is not possible, hence an important interpretation of parameter estimates in a logit model is explaining the marginal effect of each exogenous variable.

Table 2. Description of the Explanatory Variables used in binary logistic regression model.

\begin{tabular}{|c|c|c|c|c|}
\hline No & Independent variables & Description & Measurement & Expected signs \\
\hline 1 & Age of household head (AGE) & Continuous & Number & _- \\
\hline 2 & Sex of household head (SEX) & Dummy & 1 , if the household head is male, 0 , otherwise & - \\
\hline 3 & Educational level (EDUC) & Continuous & Years of schooling & - \\
\hline 4 & Family size (FAMSIZE) & Continuous & Adult Equivalent & + \\
\hline 5 & Farm income (FARMINC) & Continuous & Ethiopian Birr & - \\
\hline 6 & Off-farm income (OFFINC) & Continuous & Ethiopian Birr & - \\
\hline 8 & Credit use (CREDUSE) & Continuous & Ethiopian Birr & _- \\
\hline 9 & Distance from market (DISTMKT) & Continuous & Hour & + \\
\hline 10 & Farm land size (LNDSIZE) & Continuous & Hectare & - \\
\hline 11 & Total livestock owned (TLOWN) & Continuous & TLU & - \\
\hline 12 & Agro-Ecology (AGECO) & Dummy & 1 , if the household lives in midland; 0 in lowland & - \\
\hline
\end{tabular}

Table 3. The Marginal effect estimates of the binary logistic model regression.

\begin{tabular}{lllll}
\hline Variables & Marginal effect (dy/dx) & Std. Err & Z & P>IZI \\
\hline AGE & -0.0017901 & 0.00197 & -0.91 & 0.364 \\
SEX & 0.1226076 & 0.09288 & 1.32 & 0.187 \\
EDUC & -0.0190988 & 0.00809 & -2.36 & $0.018^{* *}$ \\
FAMSIZE & 0.0364327 & 0.01303 & 2.80 & $0.005^{* * *}$ \\
FARMINC & -0.0000162 & 0.00001 & -1.26 & 0.209 \\
OFFINC & -0.0000163 & 0.00001 & -1.78 & $0.075^{*}$ \\
DR & 0.0544538 & 0.0252 & 2.16 & $0.031^{* *}$ \\
CREDUSE & -0.0000117 & 0.00001 & -0.79 & 0.430 \\
DISTMKT & 0.0917102 & 0.05063 & 1.81 & $0.070^{*}$ \\
LNDSIZE & -0.0128525 & 0.00741 & -1.74 & $0.083^{*}$ \\
TLOWN & -0.0359545 & 0.01303 & -2.76 & $0.006^{* * *}$ \\
AGECO & -0.0373529 & 0.01933 & -1.93 & $0.053^{*}$ \\
\hline
\end{tabular}




\begin{tabular}{llll}
\hline Number of observation & $\mathbf{2 0 3}$ & Pseudo R2 & $\mathbf{0 . 3 8 8 0}$ \\
\hline LR chi2 $(12)$ & 79.27 & Log likelihood & -62.500999 \\
Prob $>$ chi 2 & 0.0000 & & \\
\hline
\end{tabular}

$* * *, * *, *$ significant at $1 \%, 5 \%$ and $10 \%$ probability level respectively.

Source: Own computations, based on household survey data, 2018.

The likelihood ratio test statistics as a measure of goodness of fit of the model exceeds the chi-square critical value with 12 degrees of freedom at less than 5 percent significance level justifying that the null hypothesis that all the slope coefficients except the intercept are simultaneously equal to zero is rejected. Therefore, the model fits the data well to discuss significant variables.

Of the twelve explanatory variables used in the model, eight variables significantly determine household's food insecurity situations both positively and negatively at $1 \%$, $5 \%$ and $10 \%$ significance level in Konso district. In the study area, farmland size, education level, off-farm income, livestock number and agro-ecology determine negatively and significantly household food insecurity. Households with large land sizes are more likely to become food secure than those who had small land size. This variable is significant at less than 10 percent probability level and negatively related to food insecurity. All other things constant, the probability of being food insecure decreased by 1.2 percent as land size increases by one hectare. Education level of the household head variable was expected to have a strong negative relationship with the probability of rural household food insecurity and it is significant to determine rural food insecurity at less than 5 percent probability level. The marginal effect result also shows that, one additional year of schooling of the household, keeping all other variables constant, decreases the probability of household to be food insecure by about 1.9 percent. Similarly, off-farm income earner households are negatively and significantly related to the probability of food insecurity in the study area. All other things constant, the probability of being food insecure decrease by 0.001 percent as off-farm income increases by one Ethiopian birr. This finding coincides with Fekadu et al. [5] the availability of off-farm/non-farm income increases the household's food security status. Also, households with a large number of livestock are more likely to become food secure significantly and negatively at less than 1 percent probability level. All other things constant, the probability of being food insecure decreased by 3.5 percent, as the number of livestock increases by one TLU. The possible explanation can be the household with large number of livestock can sell their animals to buy crops at the time of food shortage and any other food items so they can escape from the risk of food insecurity. The study finding conforms to Fekadu et al. [5] found that an increase in livestock ownership increases probability of being food secured. Equally, agro-ecology negatively and significantly at less than 10 percent probability level determines food insecurity in the study area. Households, who live in midland, are less likely to be food insecure than those who live in low land. All other things constant, the probability of being food insecure decreased by 3.7 percent, if the household lives in midland. The possible justification can be households, who live in midland has fertile soil than households, who live in lowland, and there is population pressure in midland relative to lowland but in lowland (kola) the people are less densely populated. Thus, living in midland decreases the chance of becoming food insecure in the study area.

On the other hand, family size, dependency ratio, and distance from the market determine positively and significantly household food insecurity in the study area. Family size coefficient is positive and significant at less than 1 percent level of probability. Keeping all other things constant as household size increases by one adult equivalent the probability of being food insecure increases by 3.6 percent. Similarly, dependency ratio has positive relationship which indicates that the probability of being food insecure increases as dependency ratio increases. Other things remain constant, if dependency ratio increases by one, the probability of being food insecure increases by 5.4 percent. This is because an additional dependent member shares a limited amount of food and other resources so this may lead to become food insecure. The result is in conformity with the study of Mequanent et al., [9] emphasizing that an increase in the number of non-working members of household or dependency ratio increases the food insecurity level of household. Likewise, households, who are far from market, are more likely to be food insecure. Keeping all other things constant, the probability of being food insecure increased by $9.1 \%$ as the distance from the market increase by one kilometer. This result coincides with the result of Semere, [11] that he concludes that, households who have proximity to the market center have better chance to improve their income, which in turn reduces food insecurity.

Households in Konso woreda practices four common types of coping strategies. They can engage in off-farm jobs, sales of animals, temporary migration to other area and receiving money from a productive safety net program.

Table 4. Common coping strategies practiced by households in Konso.

\begin{tabular}{lllll}
\hline Types of coping strategies & Overall (203) & Insecure (162) & Secure (41) & Rank \\
\hline Engaging in off-farm jobs & $40 \%$ & $63 \%$ & $58 \%$ & $2^{\text {nd }}$ \\
Sales of animals & $52 \%$ & $54 \%$ & $33 \%$ & $3^{\text {rd }}$ \\
Temporary migration & $23 \%$ & $30 \%$ & $7 \%$ & $4^{\text {th }}$ \\
Receiving food and money from Productive safety net & $74 \%$ & $95 \%$ & $65 \%$ & $1^{\text {st }}$ \\
\hline
\end{tabular}

N: B Percent does not sum up to 100 , due to multiple responses. 
Households were asked to rank commonly used coping strategies in the study area. About $74 \%$ of all respondents and $95 \%$ of food insecure and $65 \%$ of food secure households identified receiving food and money aid as major coping strategies used by most households and engaging in off-farm activities was the second most common coping strategy in the study area. Livestock provide hedging against the risk of food insecurity and about $52 \%$ of all sampled household and $54 \%$ of food insecure and $33 \%$ of food secure households identified animal sale as a third coping strategy in the study area. Household members migrate to another area in the region in order to get a temporary job, $23 \%$ of all respondents, $30 \%$ of food insecure household and only $7 \%$ of food secure households were used temporary migration as a fourth coping strategy.

\section{Conclusion}

Konso district faces high levels of food insecurity, ranking as one of the hungriest districts in the region. The result indicates that $80 \%$ of the households in the study area were food insecure and only $20 \%$ of households were food secure. Core food security module analysis result also indicates that, out of $80 \%$ food insecure households $32 \%$ of households were found to be mildly food insecure, $29 \%$ of them were moderately food insecure and $19 \%$ of them were severely food insecure. From the result, it is possible to say in the Konso district, majority of households were mildly food insecure.

The result of the binary logistic analysis showed that, of the twelve explanatory variables hypothesized to determine household's food insecurity in Konso district only eight variables significantly determine household's food insecurity situations both positively and negatively at $1 \%, 5 \%$ and a $10 \%$ significance level. In the study area, farmland size, education level, off-farm income, livestock number, and agro-ecology determine negatively and significantly household food insecurity. On the other hand, family size, dependency ratio and distance from market determine positively and significantly household food insecurity in Konso district

\section{Recommendations}

Government and other stakeholders should give priority in solving rural household's food insecurity problems. To solve this problem in a rural area like Konso, the focus should be given to increase education level, off-farm income, number of livestock and equal focus is also important to reduce family size through a core rural development strategy.

\section{Acknowledgements}

Above all, we would like to extend our deepest love and gratitude to St. Virgin Mary and Her Son, Jesus Christ.
Further the researchers are very keen to thank Mr. Haile Kaske, Melaku Haile and Yosef Gechate. Finally, we want to thank Arbaminch University for financing the data collection.

\section{References}

[1] Amsalu, Bekabil and Beyene (2014) 'Empirical analysis of the determinants of rural households food security in Southern Ethiopia' the case of Shashemene District.

[2] Degefa Tollosa. (2002), "Household seasonal food insecurity in Oromiya zone" Ethiopia.

[3] EHNRI (Ethiopian Health and Nutrition Research Institute), 2000, Food composition table for use in Ethiopia. Ethiopian Health and Nutrition Research Institute Part III, Addis Ababa. Ethiopia.

[4] FAO (2017) 'The state of food security and nutrition in the world'.

[5] Fekadu Beyene and Mequanent Muche (2010), Determinants of Food Security among Rural Households of Central Ethiopia: An Empirical Analysis, Quarterly Journal of International Agriculture 49 (2010), No. 4: 299-318.

[6] Gujirati, D. N. (1995): Basic Econometrics, Third Edition. McGraw-Hill, New York.

[7] Karale Kasaso (2015), "Household Food Security Status and Its Determinants in Rural Konso Woreda, Southern Ethiopia".

[8] Melkamu Mada (2011), Small-scale Agriculture and it's hope to food security in Africa: the case of kamba district in Ethiopia. International Journal of Management Research and Business Strategy, ISSN 2319-345X www.ijmrbs.com, Vol. 4, No. 2, April 2015.

[9] Mequanent Muche, Birara Endalew and Tesfalem Koricho (2014) "Determinants of Household Food Security among Southwest Ethiopia Rural Households" Department of Agricultural Economics and Extension, Jimma University, Ethiopia.

[10] RDFS, Section (2009), The Rural Development and Food Security.

[11] Semere Gebretsadik, 2008. Dimensions and Determinants of Rural Household Poverty: The Case of Eastern Zone, Tigray National Regional State. M. sc Thesis in Agricultural Economics, Alemaya University, April 2008.

[12] WFP (World food programme), 2010' The State of Food Insecurity in the World'.

[13] WFP (2013) 'Fighting Hunger World Wide': Annual Report. Ethiopia.

[14] WFP (2014) 'Comprehensive Food Security and Vulnerability Analysis (CFSVA): Executive Summary, Ethiopia.

[15] WFP (2017) 'The State of Food Security and Nutrition in the World' (SOFI) Report.

[16] Yamane, Taro (1967) Statistics: An Introductory Analysis $2^{\text {nd }}$ Edition. New York. 